\title{
Ethical Issues Concerning Vaccination Requirements
}

\author{
Alvin Nelson El Amin, MD, MPH, ${ }^{1}$ \\ Michelle T. Parra, $\mathrm{PhD},{ }^{1}$ \\ Robert Kim-Farley, MD, MPH, ${ }^{1}$ \\ Jonathan E. Fielding, MD, MPH ${ }^{1}$
}

\begin{abstract}
Vaccinations are one of public health's greatest achievements. However, an ethical dilemma lies in the balance of personal autonomy and choice versus protection of the entire at risk population. Vaccines have become readily available in most parts of the world, yet debates continue as to the appropriateness of requirements for vaccinations, including legal mandates of vaccinations during public health emergencies and more routinely for school entry. This paper addresses ethical issues concerning vaccination requirements in the context of historical as well as current immunization program activities. Five important programmatic focus areas for immunization programs are identified for minimizing conflicts among the relevant ethical principles when developing and implementing vaccination requirements; namely: 1) reviewing and evaluating current vaccination mandates in the relevant health jurisdiction; 2) increasing the use of non-compulsory vaccination strategies; 3) addressing parent/guardian vaccine safety concerns; 4) enhancing public awareness of vaccine-preventable disease risks; and 5) promoting a better public understanding of herd immunity. We suggest that strengthening these programmatic focus areas can lead to a greater public acceptance of vaccination requirements.
\end{abstract}

Key Words: Immunization, vaccination, vaccine mandates, personal belief exemption

Suggested Citation: El-Amin AN, Parra MT, Kim-Farley R, Fielding JE. Ethical issues concerning vaccination requirements. Public Health Reviews. 2012;34: epub ahead of print.

\section{INTRODUCTION}

The use of vaccines to globally eradicate smallpox and eliminate many of the major vaccine-preventable causes of childhood morbidity and mortality

\footnotetext{
${ }^{1}$ Los Angeles County Department of Public Health, Los Angeles, CA, USA.
}

Corresponding Author Contact Information: Alvin Nelson El Amin at alnelson@ph. lacounty.gov; Los Angeles County Dept of Public Health, 3530 Wilshire Blvd. Suite 700, Las Angeles, CA 90010, USA. 
as public health problems in the United States and other developed nations is one of the most important public health achievements of the last century. ${ }^{1}$ In most developed countries, vaccination has resulted in once common diseases now being rare.

Vaccination requirements, variably designated as compulsory vaccination laws and vaccine mandates, are important tools for achieving the high vaccination coverage levels that resulted in this positive impact on population health. The first such vaccination requirements were passed in Italy in 1806, France in 1810, and in Sweden in $1816 .{ }^{2}$ Proposals for vaccination requirements often precipitated vigorous discussions of ethical issues, especially among parents and guardians of infants and children targeted to receive the vaccines. In the past, these concerns impacted the extent to which vaccination requirements were enacted or, when enacted, the extent to which they could be enforced.

This paper addresses the major ethical issues felt to have been pertinent to vaccination requirements, using selected examples over the last 200 years, and provides suggestions on how to minimize ethical conflicts when developing and implementing vaccination requirements in the future. We do not imply that any of the vaccination requirements discussed herein were inappropriate or were not supported by the extant evidence base at the time they were implemented. Our focus rather is on the nature and role of ethical considerations in the implementation of vaccination requirements and possible strategies to be considered by immunization programs for gaining positive public response or alternatives to them.

\section{ETHICAL CONSIDERATIONS RELEVANT TO VACCINATION REQUIREMENTS}

The last decades of the twentieth century witnessed the emergence and consolidation of a set of core ethical principles felt to be critical to medical research, and the practice of medicine. ${ }^{3}$ These principles stressed the autonomy of the individual, not surprising given the paternalistic and authoritarian manner that sometimes characterized modern medicine in the last century. However, because public health is concerned with the health of communities and populations, in addition to the health of individuals, and because governmental authority is crucial to the implementation and sustainability of public health programs, it has become apparent that biomedical ethical frameworks are not always appropriate for defining and guiding public health activity. ${ }^{3}$ Furthermore, many of the actions that are taken to contain infectious disease epidemics or other public health emergencies could be considered paternalistic in nature. 
Over the past two decades, much activity has been directed toward the goal of defining the ethical principles relevant to public health. There is some consensus, as put forth by Childress et al. in 2002, that the most relevant of these principles (which they label moral considerations) are: 1) producing benefits; 2) avoiding, preventing, and removing harms; 3) producing the maximal balance of benefits over harms and other costs (i.e., utility); 4) distributing benefits and burdens fairly (distributive justice) and ensuring public participation, including the participation of affected parties (procedural justice); 5) respecting autonomous choices and actions, including liberty of action; 6) protecting privacy and confidentiality; 7) keeping promises and commitments; 8) disclosing information as well as speaking honestly and truthfully (i.e., transparency); and 9) building and maintaining trust. ${ }^{4}$ Childress et al. suggest that three of these moral considerations - benefiting others, preventing and removing harms, and utility — are critical to the goal of public health while three others-justice, respect for autonomy, and privacy - are most likely to limit public health activities. ${ }^{4}$

In addition to defining the ethical issues relevant to public health, we must also acknowledge that there are often instances in the practice of public health decision-making and program implementation where the above noted considerations may come into conflict, provoking a need to choose or assign a greater weight to one of these moral considerations over another. Childress et al. proposed five "justificatory conditions" to help determine when the moral considerations critical to public health (benefiting others, preventing and removing harms, and utility) can take precedence over the other goals during specific public health activities. ${ }^{4}$ These "conditions" are: effectiveness of the activity, proportionality of the activity (the probable public health benefits outweigh the "infringed" other moral considerations), necessity of the activity, the extent to which the activity represents the least infringement of the other moral considerations, and lastly, the ability to publicly justify the activity in a transparent manner. Because vaccination activities are a key component of many public health programs, we suggest that they fall within this ethical framework.

Diekema and Marcuse, however, have put forth a more direct approach for evaluating and resolving ethical issues around mandatory vaccination programs. ${ }^{5}$ Their approach is based upon the often cited medical maxim commonly translated as: "first, do no harm." When applied to vaccination activities, this maxim has the following implications: the vaccination should be of benefit to the subject being vaccinated; care should be taken to prevent any harm that might accrue from the vaccination; compared to other procedures for addressing the same issue, the vaccination should be 
the best opportunity for successfully preventing disease as compared to the risk for harm; and if harm does result from the vaccination, the benefit of vaccination to the subject should at least compensate for the harm incurred. ${ }^{5}$

Because vaccination provides not only a direct benefit (immunity to disease) to the person being vaccinated but also provides a benefit to others in the community via herd immunity, Diekema and Marcuse remind us that unvaccinated persons can be viewed as "harming" the community. ${ }^{5}$ It, therefore, follows that for serious and highly communicable diseases, there is a role for compulsory vaccination programs. Diekema and Marcuse cite the utilitarian philosopher John Stuart Mill who held that: "The only purpose for which power can rightfully be exercised over any member of a civilized community, against his will, is to prevent harm to others. His own good, either physical or moral, is not sufficient warrant." 5 This principle, known as the "harm principle," can be used to expand the application of the maxim: "first, do no harm" to the community interests that result from vaccination programs. ${ }^{5}$ It, therefore, follows that the "harm principle" can be used to justify compulsory vaccination programs in specific instances where the community interests or benefits are deemed to be significant. Often, the issue is in determining what is considered significant.

Finally, the "precautionary principle" has been put forth by Gostin and colleagues as being critical in public health's response to potential infectious disease emergencies. ${ }^{6}$ This principle was initially defined as being relevant to environmental health emergencies and asserts that public health is obligated "...to protect populations against reasonably foreseeable threats, even under conditions of uncertainty... Given the potential costs of inaction, it is the failure to implement preventive measures that requires justification..."

In the following section, we review the implementation and subsequent public response to two important compulsory vaccination programs, through the lens of the ethical issues we have just discussed, in addition to other ethical principles and legal rulings that are appropriate to the discussion.

\section{UNITED KINGDOM COMPULSORY SMALLPOX VACCINATION IN THE $1^{\text {TH }}$ CENTURY}

A compulsory smallpox vaccination law was first passed in England and Wales in 1853, later strengthened in 1867 and 1871 by adding stronger provisions for enforcement that included fines for noncompliance. ${ }^{7}$ The purpose of the law was to institute universal infant vaccination to control and eventually prevent smallpox outbreaks that were a major cause of morbidity and mortality at the time. Inherent in the law was the belief, 
somewhat evidenced-based, that the smallpox vaccination technique pioneered by Edward Jenner was a critical scientific development surpassing the previously common practice of variolation, and that smallpox vaccination, when implemented on a large scale could "...ensure the health of the social body." However, a significant percentage of the populace objected to the law and refused to be vaccinated. They considered the law to be in violation of their autonomy, their right as free people to protect their children from a procedure that had a significant incidence of "visible" side effects. ${ }^{8}$ Additionally, the incidence of smallpox at the time was on the decline and, in the minds of some, it had not been disproven that less invasive actions, including the immediate quarantine and isolation of persons known to be exposed and persons known to be infected (known as the Leicester method), would not achieve the same result as vaccination. ${ }^{9}$

From the perspective of the members of the Epidemiological Society's Smallpox Vaccination Committee it probably appeared that this was a simple conflict between beneficence and autonomy, with beneficence deserving greater weight or consideration. ${ }^{8}$ However, upon further consideration, especially considering the contextual fabric of English society at the time, where the privileged classes passed the laws that the poor and working classes were obliged to obey, it is not surprising that the moral principles of autonomy, liberty, and avoidance of harm were important to many who were affected by the compulsory law. For the poor and working classes, smallpox vaccination was not only a potentially dangerous procedure that required the "contamination" of their infant children (as in the crudest practice of the technique, pustular material was transferred from the arm of a child or adult one week after vaccination, to the arm of an unvaccinated infant), but also conflicted with the social class struggle and their aspirations for freedom and liberty. ${ }^{8}$

Additionally, objection to the law was heightened by the way in which it was implemented. Persons who did not comply with the law were fined and often fines accrued until large sums were owed. ${ }^{2,10}$ The law was also more vigorously enforced in some districts than in others. This somewhat coercive and inconsistent mechanism for implementing the law was not well tolerated.

In response to continuing and increasing opposition to the law, a Royal Commission was convened in 1889 to review the usefulness of smallpox vaccination and the compulsory vaccination law. ${ }^{2}$ After seven years of deliberation, the Commission recommended the allowance of a "conscientious exemption" for persons opposed to vaccination of their children, but made it a point to distinguish such persons from those who failed to vaccinate their children as a result of neglect or indifference. ${ }^{2}$ 
On the surface, the ability to "conscientiously exempt" would seem to improve the public's tolerance of the law. However, due to the sociopolitical issues discussed earlier and due to non-uniform implementation of the new clause (e.g., parents in some areas being vigorously "crossexamined" and bullied into accepting vaccination), opposition to the English Compulsory Vaccination law continued to grow over time until it was repealed in $1946 .{ }^{2}$ To this day, there has been no reintroduction of a childhood compulsory vaccination requirement in the UK.

Objection to the UK compulsory vaccination program was predictable, based on the five conditions considered essential by Childress et al. when public health concerns are given precedence over other important ethical concerns such as individual autonomy. Although the compulsory program probably met the "effectiveness" and "proportionality" conditions, being an effective technique with significant public health benefit, it is not clear that a non-compulsory program would not have achieved equal or better results. Additionally, the law was not implemented in a way that "least infringed" upon the autonomy of poor and working class parents because enforcement officers could make unannounced home visits to vaccinate unsupervised children. ${ }^{8}$ Finally, whatever efforts, if any, that were undertaken to justify the compulsory program and, thereby, gain the public's trust appear to have been unsuccessful for a significant segment of the population.

Regarding the other ethical principles previously discussed, the UK compulsory smallpox vaccination program probably met the conditions of the "harm principle" in that compulsory vaccination was intended to prevent the significant community harm that resulted from smallpox epidemics. Lastly, the UK program, in our opinion, met the "precautionary principle" because it met public health's "obligation" to protect the community from the "reasonably foreseeable" threat of future smallpox epidemics.

\section{MANDATORY VACCINATION AGAINST SMALLPOX, MASSACHUSETTS, UNITED STATES}

Smallpox vaccination was first implemented in the US in 1801, soon after Edward Jenner's discovery of the technique. ${ }^{11}$ In 1809, Massachusetts was the first state to pass a law requiring the general population to be vaccinated against smallpox. ${ }^{2}$ All infants were required to be vaccinated before their second birthday and again before entering public school. During smallpox epidemics, all persons who had not been vaccinated or revaccinated within the preceding five years could also be compelled to be vaccinated. ${ }^{11}$

Because vaccination proved to be safer than the previously practiced technique of variolation, it was adopted widely and credited with greatly 
decreasing the incidence of smallpox during the $19^{\text {th }}$ century. However, there was a resurgence of smallpox in 1893-1894 and many local health departments implemented ordinances requiring quarantines and vaccination. ${ }^{11}$ Although some persons refused vaccination at that time, the first major legal challenge was mounted in 1902. Henning Jacobson refused to be vaccinated because of an adverse event he claimed to have experienced when vaccinated as a child, essentially basing his protest on the ethical basis of autonomy and harm. ${ }^{12}$ He took his case to district, state, and ultimately the Supreme Court of the United States in 1905 (Jacobson v. Massachusetts), which ruled that the individual liberties guaranteed by the United States Constitution can be encroached upon when "the safety of the general public may demand." 13 Thus, the ability of local public health entities to enact such laws, despite an individual's beliefs, on behalf of the public good was upheld. In 1922, the U.S. Supreme Court, in Zucht v. King, reaffirmed the right of governmental agencies to require vaccination when it supported a school system's refusal to admit an unvaccinated child. ${ }^{14}$

Despite the U.S. Supreme Court's rulings in favor of mandatory vaccination requirements, during much of the $20^{\text {th }}$ Century, states and counties relied more on persuasion, as opposed to coercion, to achieve compliance with vaccination requirements. ${ }^{11}$ At the time of the Jacobson decision, only 11 states had mandatory vaccination laws and most were not enforced by legal penalties. By 1963, the number of states with immunization requirements for school entry had only grown to 20 . As measles outbreaks continued to occur during the 1970 s, incidence data revealed that states with strictly enforced school immunization laws had significantly fewer measles cases. ${ }^{2}$ As a result, the U.S. Department of Health and Human Services began advocating for all states to enact school immunization requirements as part of their measles eradication campaign and by 1980, all 50 states had enacted laws requiring specific immunizations for school entry. ${ }^{2}$

\section{POLICE POWERS FOR PUBLIC HEALTH}

The responsibility of the government to protect the public from the dangers of highly communicable and deadly diseases like smallpox was clearly established in the Supreme Court's 1905 Jacobson v. Massachusetts ruling. However, this responsibility existed long before the vaccine-related court ruling and was historically implemented through the "police powers" of the local health officer for many functions such as sanitation and food safety, as well as during times of extreme public health emergencies. ${ }^{15}$ The police powers of the local health officer derive from the inherent powers of state governments to provide for, and protect, the public's health-a power that 
is often delegated to local governments within the funding and requirements of state health and safety codes.

However, there are limits to these powers. ${ }^{15}$ Police powers of the local health officer, whether utilized to require vaccination of health care workers during an influenza pandemic or examination of a recalcitrant individual with a serious communicable disease, must be exercised in a non-discriminating and fair manner, as guaranteed by the US Constitution. This protects an individual's rights and helps to ensure a balance between the ethical requirements of government to ensure society's welfare and support individual autonomy in the context of justice.

\section{PATERNALISM IN VACCINATION PRACTICE}

For purposes of our discussion, we will define paternalism as the substitution of one individual's judgment (in this instance being a public health professional) in place of another's decision-making abilities, for the purpose of promoting that individual's welfare. ${ }^{16}$ As noted earlier, some aspects of public health practice can be viewed as paternalistic in nature (e.g., levying taxes on tobacco products and restricting trans-fats in food products). Compulsory vaccination laws that are implemented without regard to ethical frameworks run the risk of being viewed as paternalistic practices and, therefore, would not be expected to be implemented in the absence of a severe communicable vaccine-preventable disease emergency. However, there is another instance when paternalism in immunization practice is more likely to be tolerated. Described by others as "weak paternalism", it involves action taken to prevent harm to vulnerable persons who, as a result of young age, developmental level, or other unique situations, are not able to consent to preventive or treatment interventions. ${ }^{16}$ An example of weak paternalism is the involvement of Children Protective Services (CPS) agencies, in collaboration with public health officials and the US courts, to ensure that newborn infants receive hepatitis B postexposure prophylaxis, including vaccination with hepatitis B vaccine, when chronically infected mothers refuse to give consent. ${ }^{17}$

\section{SITUATION WITH HUMAN PAPILLOMAVIRUS VACCINE}

The human papillomavirus (HPV) vaccine, which currently targets preteen, adolescent, and young adult populations, prevents cervical cancer in women by preventing chronic HPV infection with the HPV serotypes most likely to cause cancer. ${ }^{18} \mathrm{HPV}$ infection is a sexually acquired communicable 
disease and some women acutely infected with HPV will become chronically infected and as a result later develop cancer. Although screening and treatment options exist for cervical cancer, the disease must be diagnosed early enough for the treatment to be beneficial. Despite the existence of treatment modalities, it is estimated that at least 3,900 women die from cervical cancer in the US each year. ${ }^{18}$

Vaccinating boys, in addition to girls, against HPV is felt to be important for two reasons. It has the potential to reduce transmission of HPV to girls, thereby indirectly decreasing cervical cancer. In addition, HPV vaccination of boys may also decrease the estimated 7,000 HPV associated cancers (primarily oropharyngeal, anal, and penile) that annually occur in men in the US. ${ }^{19}$

Upon US licensure of the first HPV vaccine, the vaccine's manufacturer embarked upon a campaign to encourage states to add HPV vaccine to school vaccination requirements. ${ }^{15}$ However, in the US, current attitudes and beliefs held by a significant number of parents regarding the vaccination of preteens and older assumedly non-sexually active girls against a sexually transmitted disease, created a resistance on the basis of autonomy (from a parental/ guardian perspective).$^{20}$ Avoidance of harm to their child is also a concern of some parents who question the safety of this relatively "new" vaccine.

Interestingly, in a critique of procedures implemented in one state to determine whether newly approved vaccines should become part of existing state law, Opel et al., used the harm principle to facilitate assessment of whether adolescents unvaccinated against HPV would pose a potential harm to others in the unvaccinated school population. ${ }^{21}$ They determined that there was not sufficient justification to make the HPV vaccine a school requirement. Currently, only the State of Virginia and Washington, D.C. have HPV vaccination requirements for girls entering the sixth grade..$^{20,22}$ An HPV vaccination requirement was recently implemented in one other state but was repealed due to public pressure. ${ }^{23}$

In California, a unique approach was taken to remove parental barriers to HPV vaccination of vulnerable persons. A state law was passed, allowing for minors aged 12 years and older to consent to medical care related to the prevention of sexually transmitted diseases, including obtaining HPV vaccine, without parental consent. ${ }^{24}$ This is an example of how an approach differing from a vaccination requirement provided an ethical way for government to meet the important responsibility of protecting the health and safety of vulnerable persons. Because they were deemed to be sufficiently mature to understand the need for and consent to a vaccine to prevent a sexually transmitted disease, the minor's individual right to make such decisions about their own body was put above the right of their parents to make those decisions. 


\section{PUBLIC PERCEPTION OF HARM FROM VACCINES}

Fear of harm from vaccines has been a significant reason stated by parents/ guardians for refusing vaccinations for their children. Concerns about the safety of the smallpox vaccine in England in the 1880s were acknowledged by the Royal Commission during its review of the smallpox vaccination law as they noted that "despite reports to the contrary, the use of humanized lymph (serum) to vaccinate against smallpox could spread diseases such as syphilis." ${ }^{2}$ The Commission suggested that "calf lymph [a significantly safer product] should be within the reach of all, in view of the compulsory nature and public funding of vaccination." ${ }^{2}$ It is also pertinent to note that in the US, during the time of the 1905 Jacobson challenge of the compulsory smallpox vaccination law, the anti-vaccine movement questioned the safety of the smallpox vaccine and suggested that governmental authorities were not truthful with the public about the vaccine's risk of serious side effects. ${ }^{25}$

In more recent times, an incident that changed people's perception of vaccination from beneficial to harmful occurred with the 1998 publication of the Wakefield article linking measles, mumps and rubella (MMR) vaccine to autism in Lancet (later retracted in 2010 because the findings were found to be the result of fraudulent research). ${ }^{26}$ The Wakefield article is felt to have been a key factor in the increased refusal rates for MMR vaccine noted in the UK over the past 15 years, which directly contributed to a resurgence of endemic measles and mumps in that country. ${ }^{27}$ Subsequent to the Wakefield article, more than 13 well designed studies have definitively disproved any kind of association between the MMR vaccine and autism. ${ }^{28}$

The public's concerns regarding vaccine safety must be considered in the context of the public's awareness of the seriousness and risk of acquiring a particular vaccine-preventable disease. For example, beginning in the late 1940s and continuing through the 1980s, the whole cell pertussis vaccine was the only vaccine available to prevent pertussis. Although this vaccine was accompanied by serious adverse events, including hypotonic episodes ( $0.06 \%$ of vaccinations), febrile seizures $(0.06 \%$ of vaccinations), and rarely, encephalitis (in perhaps one out of 310,000 vaccinations), the vaccine was generally well accepted when it first became available. ${ }^{29}$ This was at a time when pertussis, a serious and highly lethal disease, with its characteristic paroxysmal gasping cough easily identifiable and feared by parents, was a leading cause of childhood deaths. However, as annual numbers of pertussis cases drastically decreased (due to the effectiveness of the vaccine), and after several well-publicized reports of serious adverse events following vaccination with the whole cell vaccine, the public's acceptance of the vaccine plummeted in many countries, exemplifying a 
shift in focus from seeing vaccination as beneficent to vaccination as harmful. Public acceptance of pertussis vaccination did not return to high levels in these countries until the development, licensure, and widespread availability of acellular pertussis vaccines which are associated with significantly less adverse events than whole cell vaccines. ${ }^{29}$

\section{INCREASING VACCINE REFUSAL RATES, A NEED FOR ACTION}

Data indicate that more US parents/guardians are refusing vaccinations for their children, compared to past decades. In California, the "personal belief exemption" (PBE) rate for kindergarten school entry vaccination requirements increased by 67 percent over the ten year period 2000 to $2010 .{ }^{30}$ While the actual PBE rate in 2010 was still rather small at 2.33 percent, the percentage increase is significant. Similarly, for the US as a whole, although the most recent National Immunization Survey (NIS) completed for 2011 found vaccination coverage levels to be high for many vaccines, it was noted that "...clusters of unvaccinated children in geographically localized areas leave communities vulnerable to outbreaks of disease." ${ }^{31}$ Fifteen states were noted to have MMR coverage below 90 percent.

We suggest five practical areas of focus for national and local immunization programs that could contribute to the maintenance of a "vaccinefriendly" environment. These focus areas are: 1) reviewing and evaluating current vaccination mandates in the relevant health jurisdiction; 2) increasing the use of non-compulsory vaccination strategies; 3) Addressing parent/guardian vaccine safety concerns; 4 ) enhancing the public's awareness of vaccine-preventable disease risks; and 5) promoting a better public understanding of herd immunity. These suggested focus areas are a natural outgrowth of the discussions of vaccine-related ethical issues in the preceding sections of this paper.

\section{1) Reviewing and evaluating current vaccination mandates in the relevant health jurisdiction:}

Immunization programs should review vaccination mandates operational in their jurisdictions, in the context of the ethical frameworks presented in this paper, with the goal of minimizing and balancing ethical conflicts where possible. In countries experiencing outbreaks of vaccine-preventable diseases, there may be a need to implement mandates, where none exist.

In the US as noted earlier, all 50 states have school entry vaccination requirements. All of the requirements allow medical exemptions and additionally, 48 states allow philosophical/personal belief or religious 
exemptions. It is important to note that in a legal challenge to the lack of a religious exemption in one state (Boone v. Boozman), it was ruled that: “... the constitutional protection to freely exercise religion does not excuse an individual from compulsory immunization; in this instance, the right to free exercise of religion and parental rights are subordinated to society's interest in protecting against the spread of disease." 15

As part of its review of vaccine mandates, a state immunization program could determine that the procedures for obtaining a PBE does not allow for adequate opportunity to inform parents/guardians about the risks for vaccine preventable disease transmission in the school setting or to inform them about vaccine safety. In such instances, the immunization program could promote changes in state regulation of PBEs or in the state's school vaccination law to allow for this need to be addressed. Such changes have been recently enacted in two US states, one as recently as this year. ${ }^{32,33}$ One of the states has already documented a decrease in its PBE rate after implementation of new procedures for such exemptions. ${ }^{32}$

Finally, a review of state-mandated vaccines might lead to the identification of a vaccine that should no longer be part of a school mandate. Similarly, newly licensed vaccines might be considered for addition. To this end, at least one state has developed a systematic approach, which includes participation by community stakeholders, in determining the appropriateness of adding newly licensed vaccines to those mandated for school entry. ${ }^{21}$

\section{2) Increasing the use of non-compulsory vaccination strategies:}

An important consideration in minimizing conflicts among ethical principles relevant to vaccination requirements is the maximizing of lessthan-compulsory strategies to achieve and maintain high vaccination coverage levels. As long ago as 1896 in England, with the negative response to compulsory smallpox vaccination it was noted by some individuals that repealing the law might result in a higher level of vaccination. ${ }^{34}$

Few would argue that there are circumstances where compulsory vaccination and/or exclusion practices are readily justifiable on an ethical basis. Laws or regulations that require healthcare workers caring for critically ill or immune-compromised patients to show proof of vaccination (or serological evidence of immunity) against specific communicable diseases, or health-officer ordered exclusion of unvaccinated children (i.e., children with personal belief or medical vaccination waivers) from school during school outbreaks, are just two examples. However, in some settings, less than compulsory vaccination strategies may be more appropriate. As noted earlier, 48 state school vaccination requirements in the US are less than compulsory allowing for philosophical/personal belief or religious exemptions. Yet these 
laws have generally worked well to bring about and maintain relatively high childhood vaccination coverage levels in the US today.

Another unique approach has been implemented in Australia. At the national level, there is a system of financial incentives that provide stipends to families with fully-vaccinated children resulting in good compliance with school vaccination requirements. ${ }^{2}$ Other strategies that have been shown to improve vaccination coverage levels in the absence of compulsory vaccination laws include patient recall and reminder systems, provider reminder systems that ensure all medical encounters are utilized to assess patients for needed vaccinations, and school-located vaccination programs. ${ }^{35}$

\section{3) Addressing parent/guardian vaccine safety concerns:}

An important focus area that directly addresses the avoidance-of-harm element of the previously discussed ethical frameworks is vaccine safety. A vaccine that has a significant adverse event profile would not likely be considered a good candidate for a universal vaccination requirement.

In the US, a major focus was placed on vaccine safety with the passage of the National Childhood Vaccine Injury Act in $1986 .{ }^{36}$ The Act established the Vaccine Adverse Event Reporting System (VAERS) which standardized the reporting of all clinically significant events that occur after vaccination, even if the event is not suspected to have been caused by the vaccine. The Act also mandated the establishment of the Vaccine Injury Compensation Program, a no-fault system for resolving monetary vaccine injury claims ${ }^{37}$ It is compatible with the ethical principles previously discussed to assign to government the responsibility for compensating persons who experience adverse events that have been documented to be causally related to vaccination.

To ensure that all vaccinated persons are advised of the possible adverse events that could occur after vaccination, the Act requires that all persons or parents/guardians of persons vaccinated with Advisory Committee on Immunization Practices recommended vaccines, be given a copy of an updated Vaccine Information Statement (VIS). This helps prevent future accusations that the risks for adverse events after vaccination were not properly communicated to the person (or their parents/guardians) in an attempt to coerce the acceptance of vaccination. Also in the US, a network of Clinical Immunization Safety Assessment Centers was established in $2001{ }^{36}$ These centers provide standardized clinical assessments of persons who suffered a true vaccine adverse event, thereby, facilitating a better understanding of the pathophysiology and relevant risk factors for these events.

While it is critical to ensure that vaccines are as safe as current knowledge allows, often the public's perception about vaccine safety is not consistent 
with the scientific evidence. ${ }^{38}$ Addressing this fact/perception discordance is made more difficult because the benefit of vaccination is reflected through the prevention of disease-and a disease prevented, especially one with which the current public has little familiarity, does not serve to counterbalance the rare adverse events to vaccination that might occur.

Additionally, studies have found that a significant number of today's parents are suspicious of government and believe that government regulators and vaccine manufacturers work in collusion. ${ }^{38,39}$ Strengthening and publicizing the policies and procedures that eliminate perceived potential conflicts of interests between the bodies that regulate and recommend vaccines, and the manufacturers that produce them, could enhance the public's trust and would also address the transparency facet of the ethical framework discussed previously.

Physicians, nurses, and other direct health care providers are probably in the best position to communicate vaccine-related information, including vaccine safety, to parents/guardians and their patients. ${ }^{40} \mathrm{Health}$ care providers have the opportunity to secure the trust of parents/guardians, and relevant informal decision-makers, by demonstrating expertise and knowledge, openness and honesty, as well as concern and care, as they deliver routine health care to their patients. Research on risk-communication has identified all of the above qualities as affecting the extent to which an individual or institution is trusted. ${ }^{39}$ When parents change their minds and allow vaccination of their children, it is usually due to a conversation with the child's provider. ${ }^{41}$

\section{4) Enhancing public awareness of vaccine-preventable disease risks:}

Another important area for the attention of immunization programs is effectively enhancing the public's awareness of vaccine-preventable diseases (VPDs), their risk for acquiring them, and their risks for serious complications if they become ill with a VPD. Such awareness has the potential benefit of allowing individuals to better balance their "autonomy" concerns against the risks for harm from these diseases based on accurate disease-risk information. In the US, for example, VPD outbreaks are not as common as they once were, but they still occur. Although the public health community maintains surveillance systems to identify and help control outbreaks, outbreaks are often unreported in mass circulation media outlets and, when reported, may not highlight the key link to lapses in universal vaccination. Through more timely and expansive mass media there is an opportunity to heighten the public's awareness of these disease threats that have particular relevance for unvaccinated persons. Additionally, the public should be kept informed about the continuing outbreaks of VPDs in other parts of the world and reminded that rapid air travel creates many 
opportunities for unvaccinated persons living in countries with low disease prevalence to be exposed to these diseases. The public needs to know that even visiting their local emergency room in a large metropolitan area could expose them to a communicable VPD.

Lastly, immunization programs need to be prepared to take advantage of media opportunities that often accompany the periodic emotional media campaigns by anti-vaccination groups alleging harm from vaccines, as an untruth that is not refuted is often assumed to be true. ${ }^{40,42}$ The need for greater use of the media to inform about VPD risk is highlighted by the results of a study that reviewed media coverage concerning the MMR vaccine controversy in the UK between January and September of 2002. ${ }^{38}$ The study found that the MMR issue was presented by the media as a story about vaccine risks, not about the risks for acquiring the vaccine-preventable diseases that MMR vaccination prevents.

\section{5) Promoting a better understanding of herd immunity:}

The last area we will discuss as deserving more attention from immunization programs is promotion of the public's understanding and better appreciation of the benefits of herd immunity. In addition to the often heralded community benefits of herd immunity, people need to know that it affects them in a very direct way. ${ }^{43} \mathrm{~A}$ family's four month old infant (too young to have received all recommended vaccinations) might be totally dependent on the vaccination of all family members and others to be protected against VPDs such as measles or pertussis. Thus, the personal stake that all individuals have in community vaccination needs to be communicated when we inform people about the community/population benefits of herd immunity.

In some parts of the world, high levels of herd immunity may reflect a strong sense of social solidarity (e.g., doing what is good for the benefit of the group). The ability to promote the public's understanding and acceptance of herd immunity and its critical role in preventing or limiting outbreaks that would otherwise occur could be bolstered by additional research on how to effectively convey its meaning.

Some research suggests that parents who are unlikely to vaccinate their child may be even less likely to vaccinate when they become aware that overall vaccine coverage levels are high. ${ }^{38}$ This could prove to be a significant challenge to overcome in the US as NIS data show continued high vaccination coverage at national, state, and select large county/city levels. ${ }^{31}$ Unfortunately, there is very little reliable and up-to-date data regarding vaccination rates for the smaller cities and communities within 
major metropolitan areas in the US, and it is in these smaller communities that vaccination rates are more likely to be lower due to geographic clustering of persons opposed to vaccinations. ${ }^{44}$ Some health jurisdictions conduct periodic assessments of school compliance with vaccination requirements by auditing records at select schools. This data could be used to develop estimates of vaccination rates for communities and neighborhoods. If provided with this information, parents in communities with low vaccination rates might be more willing to protect their children by accepting the recommended vaccines.

\title{
CONCLUSION
}

Ethical issues pertaining to public health, and specifically immunization activities, are important in the implementation of and the public's response to mandatory vaccination programs. Often, some ethical principles are in conflict with others, or at the very least, are required to be given more weight than others, when mandatory vaccination campaigns are implemented. Efforts to minimize conflicts among the relevant ethical principles are important because such conflicts can feed anti-vaccination movements. We suggest that, in addition to incorporating the recommendations suggested in the ethical frameworks discussed in this paper, immunization programs can contribute to the creation of an environment where ethical principles are adequately addressed and therefore facilitate vaccination acceptance through: reviewing and evaluating current vaccination mandates in the relevant health jurisdiction with the goal of modifying them as appropriate to increase their effectiveness and acceptance; increasing the use of noncompulsory vaccination strategies; addressing parental/guardian vaccine safety concerns; enhancing the public's awareness of vaccine-preventable disease risks; and promoting a better public understanding of herd immunity.

\section{Acronyms List:}

$\mathrm{HPV}=$ human papillomavirus

MMR $=$ measles, mumps and rubella

NIS = National Immunization Survey

$\mathrm{PBE}=$ personal belief exemption

$\mathrm{VPD}=$ vaccine-preventable disease

\begin{abstract}
About the Authors: Dr. Alvin Nelson El Amin, MD, MPH is the Medical Director of the Immunization Program for the Los Angeles County Department of Public Health, a position he has held for the past 12 years. He is a Board Certified Pediatrician who practiced office pediatrics for seven years before becoming a public health professional 28 years ago. Prior to assuming his current position, he has held positions in State, County, and City Health Departments where his responsibilities have included supervision of maternal child health and communicable disease programs.
\end{abstract}


Dr. Michelle T. Parra, PhD is the Director of the Immunization Program for the Los Angeles County Department of Public Health, a position she has held for 6 years. In this role, she plans, directs and evaluates programs and services to increase immunization coverage levels and reduce the occurrence of vaccine preventable diseases in Los Angeles County. Dr. Parra has 20 years of experience working within the research and intervention field of health promotion. In addition to her role with the LA County Department of Public Health, Dr. Parra is an adjunct faculty at the University of Southern California (USC) School of Social Work where she teaches courses in Research Methods and Evaluation

Dr. Robert J. Kim-Farley, MD, MPH currently serves as the Director, Communicable Disease Control and Prevention, Los Angeles County Department of Public Health. His responsibilities include supervision of the Acute Communicable Disease Control Program, the Immunization Program, the Tuberculosis Control Program, the Veterinary Public Health and Rabies Control Program, and the Public Health Laboratory. He is a Professor with joint appointments in the Departments of Epidemiology and Community Health Sciences at the School of Public Health at the University of California at Los Angeles (UCLA). Dr. Kim-Farley previously served as a Career Epidemiology Field Officer with the Centers for Disease Control and Prevention (CDC); the World Health Organization (WHO) Representative to India and the Chairperson of the United Nations (UN) Theme Group on HIV/AIDS for the Joint UN Program on AIDS (UNAIDS) in India; the WHO Representative to Indonesia; Director of the WHO Expanded Programme on Immunization, Geneva, Switzerland; Public Health Advisor for the United States Agency for International Development (USAID), Washington, D.C.; and the Regional Advisor for the Expanded Programme on Immunization, WHO South-East Asia Regional Office (SEARO), New Delhi, India.

For the past 14 years, Dr. Jonathan E. Fielding, MD, MPH, MBA, MA has led the Los Angeles County Department of Public Health as Director and Health Officer. In this role, he is responsible for all public health functions including surveillance and control of both communicable and non-communicable diseases, and health protection (including against bioterrorism) for the County's 9.8 million residents. Dr. Fielding also serves as Commissioner of the First 5 L.A. Commission, which aims to improve the health and development of children 5 years of age and under. $\mathrm{He}$ is a Professor in the Schools of Medicine and Public Health at the University of California, Los Angeles. Dr. Fielding Chairs the HHS Secretary's expert advisory group on the 2020 Healthy People Project and the U.S. Community Preventive Services Task Force. He is a Presidential appointee and founding member of the national Advisory Group on Prevention, Health Promotion, and Integrative and Public Health.

Acknowledgements: The authors acknowledge the helpful review and suggestions provided by Steven Teutsch, MD, MPH, Chief Science Officer, Los Angeles County Department of Public Health.

Conflicts of Interest: None declared. 


\section{REFERENCES}

1. Centers for Disease Control and Prevention (CDC). Ten great public health achievements - United States, 1900 - 1999. MMWR Morb Mort Wkly Rep. 1999;48:241-3.

2. Salmon DA, Teret SP, MacIntyre CR, Salisbury D, Burgess A, Halsey NA. Compulsory vaccination and conscientious or philosophical exemptions: past, present, and future. Lancet. 2006;367:436-42.

3. Bayer R, Fairchild AL. The genesis of public health ethics. Bioethics. 2004; 18:473-92.

4. Childress JF, Faden RR, Garre RD, Gostin LO, Kahn J, Bonnie RJ, et al. Public health ethics: mapping the terrain. J Law Med Ethics. 2002;30:170-8.

5. Diekema DS, Marcuse EK. Ethical issues in the vaccination of children. In: Bayer R, Gostin LO, Jennings B, Steinbock B, (editors). Public Health Ethics: Theory, Policy and Practice. New York, NY: Oxford University Press; 2007. p.279-88.

6. Gostin LO, Bayer R, Fairchild AL. Ethical and legal challenges posed by severe acute respiratory syndrome: implications for the control of severe infectious disease threats. JAMA. 2003;290:3229-37.

7. Dudgeon JA. Development of smallpox vaccine in England in the eighteenth and nineteenth centuries. Br Med J. 1963;1(5342):1367-72.

8. Durbach N. Bodily Matters: The Anti-Vaccination Movement in England, 1853-1907. Durham: Duke University Press; 2005. p.23.

9. Fraser SM. Leicester and smallpox: the Leicester method. Med Hist. 1980; 24:315-32.

10. Stewart AJ, Devlin PM. The history of the smallpox vaccine. J Infect. 2006; 52:329-34.

11. Colgrove J. State of Immunity: The Politics of Vaccination in TwentiethCentury America. Berkeley, CA: University of California Press; 2006.

12. Mariner WK, Annas GJ, Glantz LH. Jacobson v Massachusetts: it's not your great-great-grandfather's public health law. Am J Public Health. 2005;95:58190.

13. Jacobson v. commonwealth of Massachusetts, 197 U.S. 11 (1905).

14. Zucht v. King, 260 U.S. 174 (1922).

15. Gostin LO, (editor). Public Health Law and Ethics: A Reader. Rev. \& Updated 2nd ed. Berkeley, CA: University of California Press; 2010.

16. Buchanan DR. Autonomy, paternalism, and justice: ethical priorities in public health. Am J Public Health. 2008;98:15-21.

17. Author's personal experience with Los Angeles County Department of Children and Family Services and local courts.

18. Balog JE. The moral justification for a compulsory human papillomavirus vaccination program. Am J Public Health. 2009;99:616-22. 
19. Centers for Disease Control and Prevention (CDC). Recommendations on the use of quadrivalent human papillomavirus vaccine in males - Advisory Committee on Immunization Practices (ACIP), 2011. MMWR Morb Mortal Wkly Rep. 2011;60:1705-8.

20. Charo RA. Politics, parents, and prophylaxis-mandating HPV vaccination in the United States. N Engl J Med. 2007;356:1905-8.

21. Opel DJ, Diekema DS, Marcuse EK. A critique of criteria for evaluating vaccines for inclusion in mandatory school immunization programs. Pediatrics. 2008; 122:e504-10.

22. Human Papillomavirus vaccination and reporting Act of 2007. D.C. Act 17-39, D.C. Law. No. 17-10. District of Columbia Register 2007;54:5146-8.

23. An act relating to immunization against Human Papillomavirus, HB 1098, 80thR. Sess. (TX 2007).

24. An act to amend section 6926 of the Family Code, relating to minors, AB no. 499. 2011-2012 Sess. (Ca 2011).

25. Williamson S. One hundred years ago: anti-vaccination leagues. Arch Dis Child. 1984; 59:1195-6.

26. Retraction--Ileal-lymphoid-nodular hyperplasia, non-specific colitis, and pervasive developmental disorder in children. Lancet 2010; 375:445. Retraction of: Wakefield AJ, Murch SH, Anthony A, Linnell J, Casson DM, Malik M, et al. Ileal-lymphoid-nodular hyperplasia, non-specific colitis, and pervasive developmental disorder in children. Lancet. 1998;351:637-41.

27. Isaacs D, Kilham H, Leask J, Tobin B. Ethical issues in immunisation. Vaccine. 2009;27:615-8.

28. Gerber JS, Offit PA. Vaccines and autism: a tale of shifting hypotheses. Clin Infect Dis. 2009;48:456-61.

29. Edwards KM, Decker MD. Pertussis vaccines. In: Plotkin S, Orenstein W, (editors). Vaccines. 5th ed. Philadelphia, PA: Saunders; 2008. p.467-518.

30. Immunization levels in child care and schools. Available from URL: http:// www.cdph.ca.gov/programs/immunize/Pages/ImmunizationLevels.aspx (Accessed 20 November 2012).

31. Centers for Disease Control and Prevention (CDC). National, state, and local area vaccination coverage among children aged 19-35 months-United States, 2011. MMWR Morb Mortal Wkly Rep. 2012;6135:689-96.

32. Washington State Department of Health. News release: May 17, 2012. Available from URL: http://www.doh.wa.gov/Newsroom/2012NewsReleases/12061Va ccineExemptionDecrease.aspx (Accessed 20 November 2012).

33. California Assembly Bill No. 2109. An act to amend Section 120365 of the Health and Safety Code, relating to a communicable disease. Available from URL: http://www.leginfo.ca.gov/pub/11-12/bill/asm/ab_2101-2150/ab_2109_ bill_20120930_chaptered.pdf (Accessed 20 November 2012).

34. The future of legislation on vaccination. Br Med J. 1896;2:1397-8. 
35. Guide to Community Preventive Services. Vaccinations to prevent diseases: universally recommended vaccinations. Available from URL: www. thecommunityguide.org/vaccines/universally/index.html (Accessed 20 November 2012).

36. Offit PA, Davis RL, Gust D. Vaccine safety. In: Plotkin S, Orenstein W, (editors). Vaccines. 5th ed. Philadelphia, PA: Saunders; 2008. p.1629-50.

37. Evans G, Levine EM, Saindon EH. Legal issues. In: Plotkin S, Orenstein W, (editors). Vaccines, 5th ed. Philadelphia, PA: Saunders; 2008. p.1651-176.

38. Serpell L, Green J. Parental decision-making in childhood vaccination. Vaccine. 2006;24:4041-6.

39. Larson HJ, Cooper LZ, Eskola J, Katz SL, Ratzan S. Addressing the vaccine confidence gap. Lancet. 2011;378:526-35.

40. Diekema DS. Improving childhood vaccination rates. N Engl J Med. 2012; 366:391-3.

41. Gust DA, Darling N, Kennedy A, Schwartz B. Parents with doubts about vaccines: which vaccines and reasons why. Pediatrics. 2008;122:718-25.

42. Parikh RK. Fighting for the reputation of vaccines: lessons from American politics. Pediatrics. 2008;121:621-2.

43. Dawson A. Vaccination and the prevention problem. Bioethics. 2004;18:515-30.

44. Omer SB, Enger KS, Moulton LH, Halsey NA, Stokley S, Salmon DA. Geographic clustering of nonmedical exemptions to school immunization requirements and associations with geographic clustering of pertussis. Am J Epidemiol. 2008;168:1389-96. 